\title{
A self management plan in the treatment of adult asthma
}

\author{
R BEASLEY, M CUSHLEY, S T HOLGATE
}

\author{
From the Immunopharmacology Group, Southampton General Hospital, Southampton
}

ABSTRACT To determine whether routine assessment of peak expiratory flow (PEF) in association with a self management plan based on inhaled corticosteroid use is effective in the management of $\tilde{N}$ chronic asthma, 36 consecutive adult patients with asthma attending an outpatient chest clinic were admitted to an open prospective study. Patients were treated with inhaled salbutamol and $\stackrel{\circ}{工}$ beclomethasone dipropionate in an attempt to achieve normal lung function. Each patient had $\mathrm{a}_{\overrightarrow{3}}$ "potential normal value," which was either the predicted normal or the maximum PEF value achieved by the patient, whichever was the higher. Patients measured PEF at home and if it fell by $\stackrel{5}{工}$ more than $30 \%$ from the potential normal value the dose of beclomethasone was doubled until PEF $\vec{\oplus}$ returned to previous values. If PEF fell by over $50 \%$ prednisolone was started at $40 \mathrm{mg} /$ day until PEF 0 returned to the potential normal value, then continued at $20 \mathrm{mg} / \mathrm{day}$ for the same number of days. If PEF fell to below $150-2001 / \mathrm{min}$ patients were asked to obtain emergency medical assistance. In the 30 主 patients who completed the trial the six months before and the six months after intervention with the

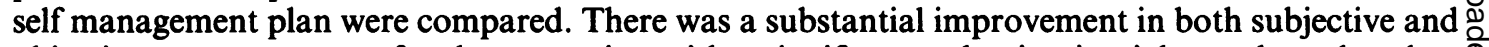

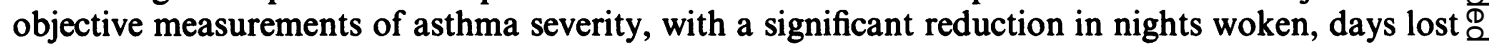
from work, and requirement for oral corticosteroids and a significant increase in baseline lung $\overrightarrow{\overrightarrow{0}}$ function. Routine measurement of PEF in association with a self management plan appears to be 3 effective in reducing symptoms of asthma and improving lung function.

\section{Introduction}

Several studies investigating the causes of death from asthma in the community have suggested that major problems exist in the management of this common disorder..$^{1-4}$ Although several factors have been identified that may contribute to death, the single most important one is a failure, not only by the patient and relative but also by the doctor, to assess and appreciate the severity and speed of onset of an acute attack and resulting in delay in initiating appropriate treatment. An explanation that could account for this observation is that symptoms alone are commonly used to assess the severity of an asthma attack, despite the well established inadequacy of this approach. ${ }^{5-7}$ Some asthmatic patients may be symptomless in the presence of substantial airflow limitation and patients with the most reactive airways have been shown to have least symptoms during an asthma attack.' These

Address for reprint requests: Professor S T Holgate, Immunopharmacology Group, Medicine 1, Centre Block, Southampton SO9 4XY.

Accepted 6 January 1989 findings suggest that regular assessment of airflow obstruction by objective means is necessary for $\frac{0}{\mathfrak{T}}$ appropriate management of these patients. The measurement of peak expiratory flow (PEF) is simple 3 and the values correlate closely with FEV ${ }_{1}^{8}{ }^{8}$ Patients keep their own PEF records satisfactorily after min- $\frac{\varrho}{3}$ imal tuition,' and measurements can be made with a Vitalograph or mini Wright meter, for which normal predicted values have been calculated. ${ }^{10}$

Other important problems identified in the asthma․ mortality studies are that relatively few patients whoN die have received adequate inhaled prophylactic treatment, and even fewer have had oral corticosteroids available for use in the severe attack. ${ }^{1-4}$ Poor com- $\omega$ pliance with treatment and difficulties with medical ${ }^{\circ}$ supervision have also been identified. In relatively fewo cases has death been considered "probably inevitable." In response to these findings we have devised a management plan specifically designed to $\frac{T}{T}$ tackle the factors that appear to have contributed to $\frac{\text { }}{\mathbb{D}}$ deaths from asthma. In an open pilot study we have? investigated the application of a management plan in the outpatient treatment of adult asthma. 


\section{Methods}

\section{SUBJECTS}

Thirty six consecutive patients with asthma attending an adult general medicine and chest outpatient clinic were enrolled in the study. The subjects comprised all new referral and follow up patients, seen in the clinic over four months, who were aged 14-60 (mean 36) years and in whom the clinical diagnosis of asthma had been made. The study was approved by the Southampton University and Hospital ethical subcommittee.

\section{STUDY DESIGN}

\section{Visit 1}

At the first visit subjects completed a questionnaire on personal details and the severity and treatment of their asthma over the preceding six months. After they had inhaled their beta $a_{2}$ bronchodilator $F E V_{1}$ and vital capacity (VC) were measured with a dry wedge spirometer (Vitalograph, Buckingham). Subjects were then asked to assess the degree of breathlessness at that time, and to record this on a visual analogue scale in which 0 indicated complete freedom from symptoms and 100 indicated severe breathlessness.

If $\mathrm{FEV}_{1}$ was under $70 \%$ of predicted normal values, inhaled beclomethasone dipropionate was started in a dose of $200 \mu \mathrm{g}$ twice daily from a metered dose inhaler; if this was already being taken the beclomethasone dose was doubled. If $\mathrm{FEV}_{1}$ was under $50 \%$ of predicted normal a two week course of oral prednisolone was prescribed, starting at a dose of $40 \mathrm{mg}$ daily. Otherwise all subjects were advised to continue with their treatment as previously prescribed. Subjects were also assessed and instructed on correct inhaler technique. A score of 1 was awarded both for coordination of activation with inspiration and for breath holding after inspiration. All subjects were given a PEF meter (Vitalograph), instructed on its use, and encouraged to measure and record PEF regularly before and after using a bronchodilator.

\section{Visit 2}

All subjects were reviewed one month later. The maximum consistent PEF value achieved by the patients was determined from their PEF recordings, and their predicted normal values were determined from standard tables. ${ }^{10}$ The higher of these two values was designated the potential normal value (PNV).

Patients were instructed to measure their PEF every morning, before inhaling their bronchodilator, and to follow the management plan (table 1). Absolute values of PEF were determined for each step in the management plan, which was provided as written instructions (table 2).

Visit 3

All patients were reviewed two months after the
Table 1 Management plan based on measurement of peak expiratory flow (PEF)

PEF measured every morning, or more frequently if unstable

PEF $\geqslant 70 \%$ potential normal value, continue "maintenance regimen" of

(a) inhaled beta sympathomimetic, twice daily and as

required

(b) inhaled beclomethasone dipropionate twice daily

PEF $<70 \%$ potential normal value:

(a) double dose of beclomethasone dipropionate for

number of days required to achieve previous baseline

(b) continue this increased dose for same number of days

(c) return to previous dose of maintenance regimen

PEF $<50 \%$ potential normal value

(a) start oral prednisolone $\mathbf{4 0} \mathbf{~ m g}$ daily and contact general practitioner

(b) continue this dose for the number of days required to achieve previous baseline

(c) reduce oral prednisolone to $20 \mathrm{mg}$ daily for same number of days

(d) stop prednisolone

PEF $<150-2001 / \mathrm{min}$

(a) contact general practitioner urgently or, if he is unavailable,

(b) contact ambulance service or, if it is unavailable,

(c) go directly to hospital

management plan had been instituted. When the patient had doubled the dose of inhaled beclomethasone frequently because of low PEF values, the increased dose became the new baseline dose taken twice daily. If a routine PEF of over $70 \%$ of the PNV had not been achieved with the maximum dose of beclomethasone used ( $2000 \mu \mathrm{g} /$ day $)$, either sodium cromoglycate or a slow release theophylline preparation (initially as a single dose at night, then as a twice daily dose with measurement of plasma concentrations) was added to the treatment regimen. When, however, the potential normal value had been achieved for the whole of the two months the treatmeit taken was reduced in the reverse order-that is, sodium cromoglycate or theophylline was withdrawn first and then the dose of beclomethasone was halved.

Table 2 Example of management plan*

Potential normal PEF† $550 \mathrm{l} / \mathrm{min}$

Routine treatment Becloforte inhaler 1 puff $2 \times$ day Ventolin (salbutamol) inhaler 1 puff $2 \times$ day and when required

PEF $<4001 / \mathrm{min} \quad$ Increase Becloforte to 1 puff $4 \times$ day and Ventolin (salbutamol) to 1-2 puffs $4 \times$ day and when required

PEF $<2501 / \mathrm{min} \quad$ Prednisolone $40 \mathrm{mg} /$ day until PEF $>$ $500 \mathrm{l} / \mathrm{min}$, then prednisolone $20 \mathrm{mg} /$ day for same number of days

PEF $<150 \mathrm{l} / \mathrm{min} \quad$ Contact general practioner urgently or go to hospital emergency department

*Example of written management plan given to a male patient aged 39 years.

tPredicted peak expiratory flow (PEF) $=540$, best consistent PEF $550 \mathrm{l} / \mathrm{min}$.

$\ddagger$ Beclomethasone dipropionate inhaler, $250 \mu \mathrm{g} /$ actuation. 
Visit 4

At the final visit, which was made three to six months after visit 3, the questionnaire was completed, FEV, and FVC were measured after bronchodilator use, and the degree of breathlessness was recorded on a visual analogue scale as at visit 1 .

\section{ANALYSIS OF RESULTS}

The severity of the symptoms assessed by questionnaire and objective measurements of the severity of asthma during the six months preceding the study and during the intervention study period were compared by means of Student's $t$ test for paired data. The correlation between the visual analogue scale scores for breathlessness and $\mathrm{FEV}_{1}$ values (expressed as percentages of predicted normal values) was determined by Spearman's rank correlation test.

\section{Results}

Six subjects withdrew from the trial within the first two months (three did not attend the clinic, two left the district, and one entered another clinical trial). Thus 30 subjects ( 19 female, 11 male) completed the trial after a mean time of follow up of seven months. Fourteen patients had been attending the clinic for a mean period of four (range $0 \cdot 3-15$ ) years. The remaining 16 were enrolled at the time of their first referral.

The asthmatic subjects who completed the trial had on entry a baseline FEV, after bronchodilator that was below that predicted, and significant morbidity with frequent nocturnal wakening and time lost from work (table 3). All but three subjects were taking regular inhaled corticosteroid or sodium cromoglycate on entry into the study, although only a few of these subjects understood the prophylactic nature of this form of treatment. Two thirds of the subjects had a satisfactory inhaler technique, achieving a score of two when assessed by an independent observer. One subject had a peak flow meter and none had a written crisis plan for use during a severe asthma attack.

There was no correlation between the assessment of breathlessness on the visual analogue scale and FEV expressed as a percentage of the potential normal value (Spearman's rank correlation coefficient, $r=0.11)$. On nine of the 16 occasions in which the $\mathrm{FEV}_{1}$ was below $70 \%$ predicted the patient was symptom free. On five of the 14 occasions in which the $\mathrm{FEV}_{1}$ was over $100 \%$ predicted the patient was breathless with a visual analogue score of over 15 .

At the final clinic visit there was significant improvement in all objective and subjective measures of asthma severity (table 3 ). The improvement was noted both in the new referral and in the long term follow up patients and was irrespective of previous inhaled corticosteroid treatment. There was a sig-
Table 3 Details of patients at initial and final visit (mean values with ranges)

\begin{tabular}{|c|c|c|}
\hline & Initial visit & Final visit \\
\hline $\begin{array}{l}\text { Lung function } \\
\text { FEV ( } \% \text { predicted) } \\
\text { FVC }(\% \text { predicted })\end{array}$ & $\begin{array}{l}75 \cdot 6(20-138) \\
87 \cdot 5(46-131)\end{array}$ & $\begin{array}{l}91.9(50-137)^{*} \\
98.9(73-127)^{*}\end{array}$ \\
\hline $\begin{array}{l}\text { Morbidity } \\
\text { Nocturnal wakening } \\
\text { Days lost }^{\mathrm{a}}\end{array}$ & $\begin{array}{r}4.3(0-14) \\
12.9(0-60)\end{array}$ & $\begin{array}{l}0.7(0-14)^{*} \\
1.7(0-30)^{*}\end{array}$ \\
\hline $\begin{array}{l}\text { Treatment requirements } \\
\text { Oral corticosteroids } \\
\text { Antibiotics } \\
\text { Inhaled corticosteroids } \\
\text { dose }(\mu \mathrm{g})^{c} \\
\text { Inhaled bronchodilator }\end{array}$ & $\begin{array}{c}0.97(0-4) \\
1.50(0-5) \\
\\
\text { (i) } 0 \\
\text { (ii) } 805(200-2000) \\
6.9(0-20)\end{array}$ & $\begin{array}{c}0.37(0-2)^{*} \\
0.57(0-3)^{*} \\
\\
350(200-1000)^{*} \\
1130(200-2000)^{*} \\
4.7(0-16)^{*}\end{array}$ \\
\hline
\end{tabular}

a: Number of nights woken due to asthma in preceding two weeks. b: Number of days lost from school or work during preceding six months.

c: Number of courses of oral prednisolone taken during preceding six months.

d: Number of courses of antibiotics taken during preceding six months.

e: Maintenance dose of beclomethasone dipropionate: (i) 8 subjects previously not taking inhaled corticosteroids, (ii) 22 subjects previously taking inhaled corticosteroids.

f: Number of puffs of inhaled bronchodilator taken per day inpo preceding two week period.

*Significance of difference (Student's $t$ test), $\mathrm{p}<0.01$

nificant reduction in requirements for inhaled bron $\sum_{3}$ chodilator, oral corticosteroids, and courses of antibiotics and a significant increase in the mainteno ance inhaled corticosteroid dose (table 3 ). In additiorp to maintenance inhaled bronchodilator and corti $\overrightarrow{0}$ costeroid treatment four patients took additiona $B$ treatment with theophylline and two with sodium? cromoglycate. One subject (aged 14) had had a good. response to sodium cromoglycate before entering the trial and this was continued during the trial with the same management regimen as was used with inhaleơ corticosteroid. Fourteen subjects were sufficiently con $\overline{5}$ fident to take oral prednisolone when their PEF felt below $50 \%$, whereas the remaining 16 subjects preferred to contact their general practitioner first. One subject taking an oral corticosteroid (pred음 nisolone $4 \mathrm{mg}$ ) was able to stop this treatment afted three months.

\section{Discussion}

In this study we have shown that a managemenci regimen based on regular objective assessment airflow obstruction in association with adequate inhaled cortocosteroid treatment is effective for adulto with chronic severe asthma. After a mean study perio $\mathscr{W}$ of seven months substantial improvement waș observed in all objective and subjective indices used to assess asthma severity. The management plan incora porated several different treatment guidelines, an their combination is likely to have contributed to this 
beneficial effect. We are aware of the open design, reliance in part on retrospective data, and lack of a matched control group in this study. We believe, however, that the magnitude of the clinical improvement and changes in drug treatment observed are far greater than could be achieved by a placebo effect alone.

The characteristics of the patients in the study highlighted the need for a management plan and in particular the need for objective assessment of lung function. Like previous authors, ${ }^{s-7}$ we found that subjects had difficulty in appreciating the degree of their airflow obstruction from symptoms alone, and on over half of all occasions when the FEV , was below $70 \%$ predicted subjects were symptom free. In contrast, other subjects experienced appreciable symptoms when FEV , was above predicted values. One of the central principles of the management plan was the regular objective assessment of lung function by the patient, using a PEF meter. Patients were instructed to make measurements at least every morning on wakening, when they are likely to be most sensitive to inadequately controlled or deteriorating asthma." Although attempts have been made to analyse PEF data in several different ways, they offer no real advantage in this setting over the simple observation of raw data as in this study.

Despite differences of opinion about the best way to treat asthma, the value of regular inhaled corticosteroids as prophylactic treatment for adults is now well established. ${ }^{12-14}$ Nevertheless, determination of the correct dose for each patient and ensuring compliance remain important problems, as we found in this study. Although most subjects were taking an inhaled corticosteroid before entering the study, their asthma was not adequately controlled with the dose administered and most were unaware that this form of treatment was different from their bronchodilator agents and had to be taken regularly. In an attempt to improve compliance all patients were maintained on beclomethasone dipropionate twice daily, with explicit instructions that the treatment should be taken at the same time, linked to some routine daily activity, such as cleaning their teeth. Inhaling corticosteroid twice daily is as effective as four times daily in patients with both mild and severe asthma, ${ }^{15} 16$ and may reduce the occurrence of oropharyngeal candidiasis. ${ }^{17}$

An important component of the management plan was the facility for patients to increase their treatment if their PEF fell below the potential normal value. In most cases this resulted in a return of PEF to the previously recorded baseline value within a few days. In this way the dose of beclomethasone dipropionate could be increased up to a maximum of $2000 \mu \mathrm{g}$ per day, above which significant adrenal suppression may occur. ${ }^{18}$ It was possible to achieve the PNV with a dose of beclomethasone dipropionate of up to $2000 \mu \mathrm{g} /$ day in all but seven patients and in these subjects sustained release theophylline or sodium cromoglycate was added to the drug regimen, depending on their previous experience with these drugs.

A final component of the management plan involved treatment of the severe asthma attack. In a previous study of asthma mortality "morning dips" with a fall in PEF of $>50 \%$ of the highest daily PEF were shown to precede sudden death. ${ }^{1920}$ For this reason we chose a fall in PEF of $>50 \%$ from potential normal values as the level at which oral corticosteroids should be introduced. Oral prednisolone was started in a dose of $\mathbf{4 0} \mathrm{mg}$ per day, which has been reported as the minimum dose necessary to produce the maximum therapeutic effect in severe asthma. ${ }^{21}$ This dose was continued until the PEF returned to $>70 \%$ PNV, when the dose was reduced to $20 \mathrm{mg}$ daily for the same number of days. The aim of this regimen was to start oral corticosteroids in sufficient dosage when required early in an attack, and to use the subsequent therapeutic response to determine the duration of this treatment.

Finally, all patients had a value of PEF at which they were advised to contact emergency helpnamely, 150-200 1/min. Facilities for direct admission to hospital have been recommended, ${ }^{22}$ but are not always available. One of our subjects required admission during the period of observation.

The effect of this management plan was assessed after a mean period of seven months. The substantial improvement observed in FEV F $_{1}$ and VC shows that relatively normal lung function can be achieved in most adults with moderate chronic asthma. Although the long term benefit of this approach has not been documented, there is some evidence to suggest that it might reduce the high mortality rate, the rapid decline in lung function, ${ }^{23}$ and the development of persistent airflow limitation, ${ }^{24}$ all features that have been associated with poor control of asthma. In this study morbidity was considerably reduced, as evidenced by a reduction both in the number of disturbed nights and in the time lost from work due to asthma. This improvement was associated with an increase in the maintenance dose of inhaled corticosteroid taken by the subjects, but with a reduction in their requirement for oral corticosteroids.

The frequent use of antibiotics by the subjects before entry into the trial suggests that a diagnosis of bacterial respiratory tract infection is often made during acute attacks of asthma, leading to unnecessary antibiotic treatment. ${ }^{25}$ The substantial reduction in antibiotic use during the study indicates that the management plan has enabled deteriorating asthma to be identified in the presence of symptoms suggesting respiratory tract infection, and appropriate anti- 
asthma treatment started.

In the present study we did not attempt to identify which features of the management plan were responsible for the improved control of asthma. The regular assessment of airflow obstruction, adequate inhaled corticosteroids, early treatment of deteriorating asthma, prevention of severe attacks, education of the patient, regular clinic attendance, and better compliance are all likely to have contributed to the overall improvement obtained. Although this study is limited by its open design and lack of matched control subjects, our results suggest that this self management plan is effective, and may provide a useful basis for the treatment of adult asthma.

We are indebted to Mrs S Foulkes and Mrs P Sleet for preparation of the manuscript, and to Vitalograph Ltd for supplying the peak flow meters. We thank the Medical Research Council of New Zealand and the Wellcome Foundation for financial support.

\section{References}

1 British Thoracic Association. Death from asthma in two regions of England. Br Med J 1982;285:1251-5.

2 Macdonald JB, Seaton A, Williams DA. Asthma deaths in Cardiff 1963-74: 90 deaths outside hospital. Br Med $J$ 1976; iii:1493-5.

3 Ormerod LP, Stableforth DE. Asthma mortality in Birmingham 1975-7: 53 deaths. $\mathrm{Br}$ Med J 1980; 280:687-90.

4 Rea HH, Sears MR, Beaglehole R, et al. Lessons from the national asthma mortality study: circumstances surrounding death. NZ Med J 1987;100:10-3.

5 McFadden ER, Kiser R, De Groot WJ. Acute bronchial asthma. Relations between clinical and physiological manifestations. N Engl J Med 1973;288:221-5.

6 Rubinfeld AR, Pain MCF. Perception of asthma. Lancet 1976;ii:822-4.

7 Burdon JGW, Juniper EF, Killian KJ, Hargreave FE, Campbell EJM. The perception of breathlessness in asthma. Am Rev Respir Dis 1982;126:825-8.

8 Lal S, Ferguson AD, Campbell EJM. Forced expiratory time: a simple test for airways obstruction. $\mathrm{Br}$ Med J 1964;i:814-7.

9 Hetzel MR, Williams IP, Shakespeare RM. Can patients keep their own peak flow records reliably? Lancel. 1979;i:597-9.

10 Gregg I, Nunn AJ. Peak expiratory flow in normaf subjects. Br Med J 1973;iii:282-4.

11 Hetzel MR. A more logical approach to asthma. Postgra Med J 1984;60:201-7.

12 Brown HM, Storey G, George WHS. Beclomethasone dipropionate: a new steroid aerosol for the treatment of allergic asthma. $\mathrm{Br} \mathrm{Med} J$ 1972:i:585-90.

13 Cameron SJ, Cooper EJ, Crompton GK, Hoare MV $\vec{\rho}$ Grant IWB. Substitution of beclomethasone aerosolfor oral prednisolone in the treatment of chronies asthma. Br Med J 1973;iv:205-7.

14 Costello JF, Clark TJH. Response of patients receiving high-dose beclomethasone dipropionate. Thorais 1974;29:571-3.

15 Tukiainen H, Vaara J, Terho E, Karttunen P, Silvasti $M_{\sim}^{\omega}$ Comparison of twice-daily and four-times daily admin응 istration of beclomethasone dipropionate in patients with severe chronic bronchial asthma. Eur $J$ Clin Pharmacol 1986;30:319-22.

16 Mecoy RJ, Laby B. Beclomethasone dipropionate ix twice daily treatment of asthma. Australian Famils̄ Physician 1980;9:721-8.

17 Toogood JH, Jennings B, Baskerville J, Anderson $\vec{J}$ Johansson SA. Dosing regimen of budenoside ando occurrence of oropharyngeal complications. Eur $t$ Respir Dis 1984;65:35-44.

18 Smith MJ, Hodson M. Effects of long-term inhaled high dose beclomethasone dipropionate on adrenal func. tion. Thorax 1983;38:676-81.

19 Hetzel MR, Clark TJH, Braithwaite MA. Asthma@ analysis of sudden deaths and ventilatory arrests in hospital. Br Med J 1977; i:808-11.

20 Bateman JRM, Clarke SW. Sudden death in asthma Thorax 1979;34:40-4.

21 Webb JR. Dose response of patients to oral corticosteroid. treatment during exacerbations of asthma. $\mathrm{Br} \mathrm{Med} \mathrm{F}$ 1986;292:1045-7.

22 Crompton GK, Grant IWB, Bloomfield P. Edinburghk Emergency Asthma Admission Service: report on $1 \dot{\Phi}$ years' experience. $\mathrm{Br} \mathrm{Med} J$ 1979;ii:1199-201.

23 Peat JK, Woolcock AJ, Cullen K. Rate of decline of lung function in subjects with asthma. Eur $J$ Respir Dis 1987;70:171-9.

24 Brown PJ, Greville HW, Finucane KE. Asthma and irreversible airflow obstruction. Thorax 1984;39:131-6

25 Hudgel DW, Langston L, Selner JC, McIntosh K. Vira仿. and bacterial infections in adults with chronic asthman Am Rev Respir Dis 1979;120:393-7. 